\title{
Cognitive function after spinal cord injury
}

\section{A systematic review}

Rahul Sachdeva, PhD, Feng Gao, MD, PhD, Chetwyn C.H. Chan, PhD, and

Andrei V. Krassioukov, MD, PhD, FRCPC

Neurolog ${ }^{\circledR}$ 2018;91:611-621. doi:10.1212/WNL.0000000000006244

\author{
Correspondence \\ Dr. Krassioukov \\ andrei.krassioukov@vch.ca
}

\section{Abstract}

\section{Objective}

To systematically examine the incidence of cognitive impairment in individuals with spinal cord injury (SCI), as well as identify potential contributing and confounding factors.

\section{Methods}

Studies quantitatively reporting cognitive ability after spinal cord injury were searched electronically via Medline, CINAHL, Embase, and PsycINFO. Manual screening for references within articles was also performed. A total of 2,481 studies were screened and a total of 70 were included in this review, 21 reporting cognitive function after SCI compared to an able-bodied control group and 49 with no able-bodied controls. Studies were analyzed for the incidence of impairment and the interactions with concomitant traumatic brain injury, psychological or somatic complaints, decentralized cardiovascular control, sleep apnea, neurologic level of injury, and age.

\section{Results}

There is a high volume of evidence reporting substantial cognitive impairment in individuals with SCI. Potential co-contributors include concomitant brain injury, psychological or somatic comorbidities, decentralized cardiovascular control, and sleep apnea. Cognitive functioning was negatively correlated with age. No clear agreement was found for the incidence of cognitive impairment or its association with level of injury.

\section{Conclusion}

Current evidence suggests that individuals with SCI should be examined and addressed for cognitive impairment. Future studies aimed at identifying potential secondary causative factors should employ stringent controls for co-occurring brain trauma since it appears to be a major contributor and confounder to impaired cognition.

\footnotetext{
From the International Collaboration on Repair Discoveries (ICORD) (R.S., A.V.K.) and Department of Medicine, Division of Physical Medicine and Rehabilitation (R.S., A.V.K.), University of British Columbia, Vancouver, Canada; Department of Spinal and Neural Functional Reconstruction (F.G.), China Rehabilitation Research Center, Beijing, China; Faculty of Rehabilitation Medicine (F.G.), Capital Medical University, Beijing, China; and Applied Cognitive Neuroscience Laboratory, Department of Rehabilitation Sciences (C.C.H.C.), The Hong Kong Polytechnic University, Hung Hom, Kowloon, Hong Kong.

Go to Neurology.org/N for full disclosures. Funding information and disclosures deemed relevant by the authors, if any, are provided at the end of the article.
} 


\section{Glossary}

CBF $=$ cerebral blood flow; FIM $=$ Functional Independence Measure; HCT $=$ Halstead Category Test; NUCOG = Neuropsychiatry Unit Cognitive Assessment Tool; OSA = obstructive sleep apnea; SCI = spinal cord injury; $\mathbf{T B I}=$ traumatic brain injury.

Spinal cord injury (SCI) is a physically and psychologically debilitating event, where an individual faces immediate and potentially permanent life changes. ${ }^{1-5}$ Prior to the 1940 s, only $10 \%-20 \%$ of individuals survived longer than a few weeks after injury. ${ }^{6}$ Technological advancements have dramatically improved these figures, with up to $90 \%$ of individuals now surviving past the first year of injury and nearly $50 \%$ surviving for 40 years postinjury. ${ }^{7}$ This has led to the expansion of rehabilitation programs to include gainful employment and community reintegration rather than merely focusing on survival and return of physical function. ${ }^{8}$ Consequently, following acute care, patients undergo exhaustive rehabilitation that involves extensive learning, practicing, and integrating radically new skills. ${ }^{9}$ This daunting task can be severely impeded by impairments in cognitive domains such as memory, learning, and social communication. Therefore, to improve quality of life after SCI, it is important to assess cognitive status and develop focused rehabilitation strategies to mitigate cognitive impairments.

Pioneering work on cognitive health after SCI showed that up to $64 \%$ of injured individuals were cognitively impaired. ${ }^{10}$ Several subsequent studies have confirmed significant impairments in various cognitive domains as well as the presence of depression and anxiety. ${ }^{2,4,11-13}$ According to a recent report, individuals with SCI have an increased risk of cognitive impairment, approximately 13 times higher than able-bodied individuals. ${ }^{14}$ Moreover, cognitive impairment is also a strong predictor of poor social participation postdischarge with 8.4 to 1 odds against employment. ${ }^{15}$ In refining the existing care and rehabilitation guidelines, the magnitude of this problem needs to be systematically evaluated. However, some of the early reviews of cognitive impairment after SCI were published in the $1990 \mathrm{~s},{ }^{2,4}$ while others were conducted in light of more focused situations, such as a concomitant traumatic brain injury (TBI) $)^{16,17}$ or impaired cardiovascular control. ${ }^{18,19}$ None of these reviews is systematic and therefore many relevant studies may have been missed.

Although many studies reported cognitive decline after SCI, the specific findings vary in terms of incidence and the degree of impairment. This is likely due to factors such as the type of test used, neurologic level of lesion, age, educational background, premorbid psychological/learning disabilities, and alcohol and substance abuse. Furthermore, it is also necessary to investigate the effect of other secondary conditions commonly present among individuals with SCI, e.g., TBI, depression, anxiety, pain, fatigue, cardiovascular dysfunction, and sleep apnea. This review specifically addresses the following questions:

1. What is the current agreement across published studies on the presence of cognitive impairment after SCI?

2. What is the estimated incidence of cognitive impairment after SCI?

3. What are the contributions or confounding effects of a concomitant TBI?

4. Does the presence of psychological comorbidities affect cognitive functioning?

5. Does decentralized cardiovascular control affect cognitive function?

6. Does sleep apnea affect cognitive ability after SCI?

7. Does the neurologic level of lesion correlate with severity of cognitive impairment?

8. Does age affect cognitive function after SCI?

\section{Methods}

\section{Search strategy}

The search, screening, and selection process was conducted in accordance with Preferred Reporting Items for Systematic Reviews and Meta-Analyses guidelines. ${ }^{20}$ A keyword literature search was conducted for all scientific publications between 1946 and the present investigating the interaction between SCI and cognitive function in humans via the following databases: Medline, CINAHL, Embase, and PsycINFO. The various keywords for cognitive impairment were searched with SCI keywords using Boolean operators (table e-1; doi. org/10.5061/dryad.rj74424). A manual search was also conducted within the references of relevant articles.

\section{Eligibility criteria}

Only studies reporting a quantitative measure of cognitive function after traumatic or nontraumatic SCI were chosen for analysis. Studies were excluded if cognitive function was not reported based on a quantifiable test. Conference abstracts, narrative reviews, and studies published in languages other than English were also excluded. Multiple publications using the same cohort (or a subset of the cohort) were considered for inclusion only when a different outcome measure was reported. In order to produce an unbiased comprehensive review covering most reports of cognitive function after SCI, studies were also included if (1) cognitive function after SCI was reported without comparison against able-bodied controls and (2) cognitive assessment was not the primary goal of the study, but was quantitatively reported. These studies are presented separately in table e-3 (doi.org/10.5061/dryad. 
rj74424). Two authors (R.S. and A.V.K.) independently screened all the studies for eligibility criteria. All discrepancies were discussed and resolved by a mutual consensus.

Data were extracted into a table format to depict participants, time since injury, and the types of tests utilized to assess cognitive function. A summary statement of the main outcomes was also generated.

\section{Results}

A total of 2,481 articles were retrieved through the electronic search. Individual case studies or case series were excluded with 2 exceptions ${ }^{21,22}$ where the cases were compared to a group of appropriately matched controls. Balanced inclusion of case studies has been suggested to increase the evidence base and strengthen the credibility of systematic reviews. ${ }^{23}$ A total of 151 full-text studies were reviewed for eligibility and 70 were included (figure e-1; doi.org/10.5061/dryad.rj74424).

Of the 70 studies selected for this review, 21 (table e-2; doi.org/ 10.5061/dryad.rj74424) directly compared cognitive function between individuals with SCI and able-bodied controls. In the remaining 49 studies (table e-3; doi.org/10.5061/dryad. rj74424) that did not include an able-bodied control group, the results were reported based on normative data. We first analyzed studies to estimate the incidence of cognitive deficits reported among participants with SCI (table 1). Further analyses included various factors that can potentially contribute to cognitive decline after SCI, such as concomitant TBI (table 2), psychological comorbidities (table 3), decentralized cardiovascular control (table 4), sleep apnea, age (table 5), and neurologic level of lesion (table 6). Some articles were used to address more than one question. Therefore, the studies shown in tables 1 and 6 are the subsets of studies listed in tables e- 2 and e-3 (doi.org/10.5061/dryad.rj74424) and are discussed based on the most pertinent outcomes.

\section{Is cognition impaired after $\mathrm{SCl}$ ?}

Considerable heterogeneity was observed across studies in terms of study design, type of cognitive tests utilized, as well as the various domains of cognition assessed such as attention, concentration, executive function, memory, processing speed, and cognitive flexibility. Significant impairment in one or more of these cognitive domains after SCI was reported in the majority of studies (38/70). Of the 21 studies with able-bodied controls, 15 showed impaired cognition and 6 reported no significant alterations in individuals with SCI (table e-2; doi.org/10.5061/dryad. rj74424). Of the 49 studies with no able-bodied controls, 23 showed significant impairments in cognitive functioning while 26 studies reported scores to be within the normative range (table e-3; doi.org/10.5061/dryad.rj74424).

\section{Incidence of cognitive impairment after SCI}

To estimate the overall effect of cognitive impairment after SCI, studies were inspected for the proportion of participants
Table 1 Studies reporting the incidence of cognitive impairment after spinal cord injury (SCI)

\begin{tabular}{|c|c|}
\hline Authors, year & Incidence \\
\hline $\begin{array}{l}\text { Davidoff et al., } \\
1985^{24}\end{array}$ & $57 \%(\mathrm{HCT})$ \\
\hline $\begin{array}{l}\text { Wilmot et al., } \\
1985^{10}\end{array}$ & $64 \%$ (Neuropsychological test battery) \\
\hline Roth et al., $1989^{25}$ & $\begin{array}{l}\text { PA-recall (40\%), Rey-recognition (31\%), VOCAB } \\
(24 \%), \text { RAVLT (10\%), HCT (12\%) }\end{array}$ \\
\hline $\begin{array}{l}\text { Davidoff et al., } \\
1990^{26}\end{array}$ & $\begin{array}{l}\text { FIM ( 0\%), LM (4\%), PA (3\%), VOCAB (38\%), RAVLT } \\
(63 \%), \text { HCT }(12 \%)\end{array}$ \\
\hline
\end{tabular}

\begin{tabular}{ll}
\hline $\begin{array}{l}\text { Radanov et al., } \\
\mathbf{1 9 9 3}^{\mathbf{2 1}}\end{array}$ & $\begin{array}{l}\text { 100\% Based on NCT (likely due to small sample size } \\
\text { and direct brainstem damage) }\end{array}$
\end{tabular}
$1993^{21} \quad$ and direct brainstem damage)

Dowler et al., $\quad 41 \%$ Using SDMT and Stroop test (processing speed)
$1995^{27}$
$1995^{27}$

Dowler et al., $\quad 60 \%$ (Neuropsychological test battery)
$1997^{36}$

$1997^{36}$

\begin{tabular}{ll}
\hline $\begin{array}{l}\text { Strubreither } \\
\text { et al., } \mathbf{1 9 9 7}^{\mathbf{2 8}}\end{array}$ & $14.50 \%$ (Tests for OPS) \\
\hline Hall et al., 199929 & $\begin{array}{l}10 \%-20 \% \text { (Ceiling effect) at discharge, 3\%-11\% at } \\
\text { year 1, 0\% by year 2 based on FIM scale }\end{array}$ \\
\hline $\begin{array}{l}\text { Borgaro et al., } \\
\mathbf{2 0 0 3}^{\mathbf{3 0}}\end{array}$ & $\begin{array}{l}\text { Orientation to time (35.3\%), orientation to place } \\
\text { (5.9\%) based on BNIS }\end{array}$
\end{tabular}

\begin{tabular}{ll}
\hline $\begin{array}{l}\text { Masedo et al., } \\
\mathbf{2 0 0 5}^{\mathbf{3 7}}\end{array}$ & $\begin{array}{l}12 \% \text { and } 24 \% \text { in communication and social cognition } \\
\text { domains respectively on FIM self-report }\end{array}$
\end{tabular}
$2005^{37} \quad$ domains respectively on FIM self-report

Holtslag et al., $\quad 75 \%$ Based on HISC (not controlled for other severe $\mathbf{2 0 0 7}^{\mathbf{3 1}} \quad$ trauma)

\begin{tabular}{ll}
\hline $\begin{array}{l}\text { Tolonen et al., } \\
\mathbf{2 0 0 7}^{\mathbf{3 2}}\end{array}$ & $\begin{array}{l}\text { 67.7\% Based on a neuropsychological test battery (all } \\
\text { impaired individuals had concomitant TBI) }\end{array}$ \\
\hline $\begin{array}{l}\text { Bradbury et al., } \\
\mathbf{2 0 0 8}^{\mathbf{3 3}}\end{array}$ & $\begin{array}{l}\text { Incidence reported only for FIM scale: SCI (0\%), SCI + } \\
\text { TBI (30\%) }\end{array}$ \\
\hline
\end{tabular}

Macciocchi et al., 1.33 SD below normative data: HVLT (34.9\%), WAIS-3

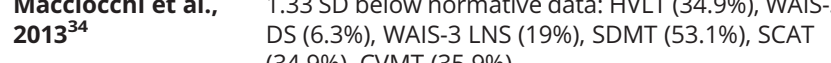
(34.9\%), CVMT (35.9\%)

\begin{tabular}{ll}
\hline Purohit et al., & FIM cognitive score $<5$ : comprehension (35\%), \\
$\mathbf{2 0 1 4}^{35}$ & expression (34\%), social interaction (39\%), memory \\
& (45\%), problem solving (50\%)
\end{tabular}

Zonfrillo et al., FIM cognitive score at or below 5: $52 \%$ of individuals $\mathbf{2 0 1 4}^{\mathbf{3 8}} \quad$ with tetraplegia and $33 \%$ of those with paraplegia at admission and 19\% (both groups) at discharge

Craig et al., 2017 1 14 SD below the normative data (28.6\%), 2 SD below the normative data (16.6\%) based on NUCOG

Abbreviations: BNIS = Barrow Neurological Institute Screen; CVMT = Continuous Visual Memory Test; DS = digit span; FIM = Functional Independence Measure; HCT = Halstead Category Test; HISC = Head Injury Symptom Checklist; HVLT = Hopkins Verbal Learning Test; LM = logical memory; LNS = letter-number sequencing; $\mathrm{NCT}=$ Number Connection Test; NUCOG = Neuropsychiatry Unit Cognitive Assessment Tool; OPS = Organic Psychic Syndrome; PA = Paired Associates; RAVLT = Rey Auditory Verbal Learning Test; SCAT = Category TestShort Form; SDMT = Symbol Digit Modalities Test; TBI = traumatic brain injury; VOCAB = Vocabulary Subtest (WAIS); WAIS = Wechsler Adult Intelligence Scale.

scoring in the impaired range. A total of 18 studies matched the criteria (table 1). ${ }^{10,14,21,24-38}$

Eight studies utilized the comprehensive neuropsychological test battery. ${ }^{10,25-28,32,34,36}$ Early reports by Wilmot et al. ${ }^{10}$ and 
Table 2 Studies reporting the effect of a concomitant traumatic brain injury (TBI)

\begin{tabular}{|c|c|c|}
\hline Author, year & Type of SCI & Outcomes \\
\hline Davidoff et al., $1985^{24}$ & Both traumatic and nontraumatic & $\begin{array}{l}\text { Mean HCT scores were abnormal for both } \mathrm{SCl}+\mathrm{TB} \text { groups; however, no } \\
\text { statistical significance was seen }\end{array}$ \\
\hline Wilmot et al., $1985^{10}$ & Traumatic & $\begin{array}{l}43 / 67 \text { (64\%) Of the patients scored as mildly impaired to worse on } \\
\text { a neuropsychological test battery }\end{array}$ \\
\hline Richards et al., $1988^{45}$ & Traumatic & $\begin{array}{l}\text { Scores were in the impaired range for HCT at first test; recovery was seen at } \\
\text { retest in a pattern similar to TBI }\end{array}$ \\
\hline Strubreither et al., $1997^{28}$ & Both traumatic and nontraumatic & $\begin{array}{l}47 / 65 \text { (72.3) Of the patients with a cerebral lesion showed minor to severe } \\
\text { degrees of impairment on OPS tests }\end{array}$ \\
\hline Tolonen et al., $2007^{32}$ & Traumatic & $\begin{array}{l}\text { On a neuropsychological test battery, } 21 \text { individuals showed cognitive } \\
\text { impairment; i.e., } 67.7 \% \text { of the total sample and } 91.3 \% \text { of the SCI + TBI subgroup }\end{array}$ \\
\hline Bradbury et al., $2008^{33}$ & Traumatic & $\begin{array}{l}\text { Cognitive function was more impaired in } \mathrm{SCI}+\mathrm{TBI} \text { group based on } \\
\text { neuropsychological battery; no significant difference was seen using FIM (ceiling } \\
\text { effect) }\end{array}$ \\
\hline Macciocchi et al., $2004^{47}$ & Traumatic & $\begin{array}{l}\text { Persons with } \mathrm{SCI}+\mathrm{TBI} \text { showed more impaired cognitive FIM score at admission } \\
\text { and discharge from rehabilitation }\end{array}$ \\
\hline Macciocchi et al., $2008^{42}$ & Traumatic & TBI severity was associated with lower cognitive FIM scores \\
\hline Macciocchi et al., $2012^{46}$ & Traumatic & $\begin{array}{l}\text { Moderate and severe TBI (but not mild TBI) was associated with additional } \\
\text { cognitive decline on FIM scale compared to SCI alone }\end{array}$ \\
\hline Macciocchi et al., $2013^{34}$ & Traumatic & $\begin{array}{l}\text { No additional effect of mild TBI on cognitive decline after } \mathrm{SCl} \text { on } \\
\text { a neuropsychological test battery }\end{array}$ \\
\hline Nott et al., $2014^{41}$ & Traumatic & $\begin{array}{l}\text { No additional effect of a concomitant TBI on cognitive decline after SCl using the } \\
\text { FIM scale }\end{array}$ \\
\hline
\end{tabular}

Abbreviations: FIM = Functional Independence Measure; HCT = Halstead Category Test; OPS = Organic Psychic Syndrome; SCI = spinal cord injury .

Davidoff et al. ${ }^{26}$ reported the incidence of impairment at $64 \%$ and between $3 \%$ and $63 \%$, respectively. However, the effect of TBI cannot be ruled out. The incidence of $14.5 \%$ reported by Strubreither et al. ${ }^{28}$ was alarmingly high for participants with a comorbid TBI (72.3\%). When excluding the individuals with TBI, Roth et al. ${ }^{25}$ reported the incidence of cognitive impairment between $10 \%$ and $40 \%$ across multiple tests. Interestingly, Macciocchi et al. ${ }^{34}$ showed that $6.3 \%-53.1 \%$ of participants with SCI were impaired across various cognitive domains regardless of a comorbid TBI. In a more chronic setting, Dowler et al. ${ }^{27}$ reported that 17 years post SCI, the majority of individuals were indistinguishable from controls in memory, attention, executive function, and visuospatial skills, with only processing speed impaired in $41 \%$ of the sample. However, a follow-up study by this group used cluster analysis to show that $60 \%$ of the participants with SCI were impaired in at least one cognitive domain. ${ }^{36}$ An incidence of $67.7 \%$ was also reported by Tolonen et al. ${ }^{32}$; however, all impaired individuals in this report met the diagnostic criteria for TBI.

Five studies reported the incidence of cognitive impairment using individual tests. ${ }^{14,21,24,30,31}$ Based on the Halstead Category Test (HCT), Davidoff et al. ${ }^{24}$ reported impairment in $57 \%$ of participants. In a later study, Borgaro et al. ${ }^{30}$ used Barrow Neurological Institute Screen to report impaired orientation to time in $35.3 \%$ of individuals. A much higher incidence $(75 \%)$ was reported by Holtslag et al. ${ }^{31}$ using the
Head Injury Symptom Checklist. These participants, however, were major trauma survivors and the effect of other trauma was not controlled for. Similarly, a study analyzing 7 patients with whiplash syndrome (with cervical SCI) reported cognitive impairment in all participants using a number connection test. ${ }^{21}$ However, this study had a much smaller sample size and cognitive impairment was likely a result of direct brainstem damage. Finally, more recent work by Craig et al. ${ }^{14}$ showed that $28.6 \%$ of participants with SCI scored 1 SD below normal on the Neuropsychiatry Unit Cognitive Assessment Tool (NUCOG).

Five studies reported the incidence of cognitive impairment using the Functional Independence Measure (FIM) instrument. ${ }^{29,33,35,37,38}$ The largest of these $(n=233,778)$ by Purohit et al..$^{35}$ showed the incidence of impairment across comprehension (35\%), expression (34\%), social interaction (39\%), memory (45\%), and problem-solving (50\%) acutely after SCI. Zonfrillo et al. ${ }^{38}$ reported impaired cognition in $52 \%$ of participants with tetraplegia and $33 \%$ of those with paraplegia at the time of admission and $19 \%$ in both groups at discharge. Interestingly, Hall et al. ${ }^{29}$ analyzed 3,971 individuals with SCI at the time of discharge and performed followup assessments at years 1, 2, and 5 using the FIM scale. This study showed major ceiling effects in $80 \%-90 \%$ of patients at discharge. This range further improved to $89 \%-97 \%$ at year 1 and $\sim 100 \%$ by year 2 . Similar ceiling effects (i.e., no 
Table 3 Studies investigating the effect of psychological/somatic comorbidities

\begin{tabular}{|c|c|c|c|c|}
\hline Author, year & Tests for cognitive function & $\begin{array}{l}\text { Tests for psychological } \\
\text { comorbidities }\end{array}$ & Correlation & Control for TBI? \\
\hline $\begin{array}{l}\text { Dowler et al., } \\
1995^{27}\end{array}$ & $\begin{array}{l}\text { SDMT, Stroop test, WMS, } \\
\text { CVLT, WRMT, WAIS-R, PASAT, } \\
\text { COWAT, WCST, HVOT, Line } \\
\text { orientation }\end{array}$ & MMPI & $\begin{array}{l}\text { MMPI scores were associated } \\
\text { with poorer processing speed }\end{array}$ & $\begin{array}{l}\text { Selectively included the } \\
\text { participants with traumatic } \\
\text { SCI with a greater possibility of } \\
\text { co-occurring TBI }\end{array}$ \\
\hline $\begin{array}{l}\text { Shnek et al., } \\
1997^{50}\end{array}$ & $\begin{array}{l}\text { Cognitive beliefs } \\
\text { questionnaire }\end{array}$ & CES-D & $\begin{array}{l}\text { Cognitive distortions were } \\
\text { correlated with depression }\end{array}$ & $\begin{array}{l}\text { Severe head injury cases were } \\
\text { excluded }\end{array}$ \\
\hline Tun et al., $1997^{51}$ & $\begin{array}{l}\text { Digit span, SWS, LWS, prose } \\
\text { recall, CFQ, DAQ, MIA }\end{array}$ & GDS & $\begin{array}{l}\text { No correlation of depression } \\
\text { with cognitive test scores }\end{array}$ & $\begin{array}{l}\text { None of the participants had } \\
\text { a concomitant TBI }\end{array}$ \\
\hline $\begin{array}{l}\text { Murray et al., } \\
2007^{52}\end{array}$ & $\begin{array}{l}\text { Self-perceived cognition } \\
\text { (RNBI) }\end{array}$ & Pain subscale of RNBI & $\begin{array}{l}\text { Pain was associated with } \\
\text { cognitive impairment }\end{array}$ & $\begin{array}{l}\text { Participants had no history of } \\
\text { TBI }\end{array}$ \\
\hline $\begin{array}{l}\text { Jegede et al., } \\
2010^{53}\end{array}$ & $\begin{array}{l}\text { WAIS, CVLT, COWAT, oral } \\
\text { trails, Stroop test }\end{array}$ & BDI-II & $\begin{array}{l}\text { No correlation of depression } \\
\text { with cognitive function }\end{array}$ & $\begin{array}{l}\text { Incidence of TBI was not } \\
\text { different between the groups }\end{array}$ \\
\hline $\begin{array}{l}\text { Clarke et al., } \\
2012^{54}\end{array}$ & $\begin{array}{l}\text { PACCQ, RAVLT, Rey- } \\
\text { Osterrieth, trail-making, } \\
\text { SDMT, COWAT, WAIS }\end{array}$ & HADS, NEO 5-factor inventory & $\begin{array}{l}\text { No correlation with cognitive } \\
\text { function }\end{array}$ & $\begin{array}{l}\text { Included participants had no } \\
\text { injury to the brain }\end{array}$ \\
\hline Craig et al., $2012^{56}$ & lowa fatigue scale & DASS & $\begin{array}{l}\text { Cognitive tiredness was linked } \\
\text { with depression }\end{array}$ & $\begin{array}{l}9 \text { Of } 41 \text { participants }(22 \%) \text { had } \\
\text { a mild TBI }\end{array}$ \\
\hline Craig et al., $2015^{55}$ & NUCOG & Psychiatric interview, HADS & $\begin{array}{l}\text { Higher cognitive capacity } \\
\text { suggested lower odds of } \\
\text { psychological disorder }\end{array}$ & $\begin{array}{l}21.5 \% \text { Of participants had } \\
\text { concomitant TBI }\end{array}$ \\
\hline Craig et al., $2017^{55}$ & NUCOG & $\begin{array}{l}\text { Psych interview, numeric pain } \\
\text { scale, HADS }\end{array}$ & $\begin{array}{l}\text { Pain was higher in individuals } \\
\text { with cognitive impairment; no } \\
\text { effect of fatigue }\end{array}$ & Same as Craig et al., 2015 \\
\hline
\end{tabular}

Abbreviations: BDI = Beck Depression Inventory; CES-D = Center for Epidemiologic Studies Depression Scale; CFQ = Cognitive Failures Questionnaire; COWAT = Controlled Oral Word Association Test; CVLT = California Verbal Learning Test; DAQ = Divided Attention Questionnaire; DASS = Depression Anxiety Stress Scales; DSM = Diagnostic and Statistical Manual of Mental Disorders; FSS = Fatigue Severity Scale; GDS = Geriatric Depression Scale, HADS = Hospital Anxiety and Depression Scale; LWS = Loaded Word Span; HVOT = Hooper Visual Organization Test; MIA = Metamemory In Adulthood; MMPI = Minnesota Multiphasic Personality Inventory; NUCOG = Neuropsychiatry Unit Cognitive Assessment Tool; PASAT = Paced Auditory Serial Addition Test; RAVLT = Rey Auditory Verbal Learning Test; RNBI = Ruff Neurobehavioral Inventory; SCI = spinal cord injury; SDMT = Symbol Digit Modalities Test; SWS = Simple Word Span; TBI = traumatic brain injury; WAIS-R = Wechsler Adult Intelligence Scale-Revised; WCST = Wisconsin Card Sort Test; WMS = Wechsler Memory Scale; WRMT = Warrington Recognition Memory Test; PACCAQ = Post-Hospital Admission Cognitive Complaint Questionnaire.

impairment) were reported by Bradbury et al..$^{33}$ in $100 \%$ of participants and by Masedo et al. ${ }^{37}$ in communication (88\%) and social cognition $(76 \%)$. These studies challenged the validity of FIM for cognitive assessment after SCI. The concerns regarding the reliability and use of FIM are discussed later.

The majority of studies report the frequency of cognitive impairment between $10 \%$ and $60 \%$; however, there are also multiple reports of no impairment as well as one report of all participants being significantly impaired. Thus, no reliable conclusions can be drawn. The lack of a clear agreement on the incidence of cognitive impairment is possibly attributed to the heterogeneity in the sample population, sample size, study design, time since SCI, types of tests utilized, and the statistical analyses performed.

\section{Effect of a concomitant TBI}

Among the most frequent causes of SCI are high kinetic/rapid deceleration accidents such as motor vehicle collisions, falls, sports, and violence. ${ }^{39}$ Since these accidents are also the most common etiologies for TBI, ${ }^{40} 16 \%-59 \%$ of SCI cases report a concomitant $\mathrm{TBI}^{41-43}$ TBI is associated with clinical manifestations of cognitive impairment including attention deficit, memory loss, and lower executive ability. ${ }^{44}$ With the increasing clinical awareness of its co-occurrence with SCI, TBI is often presumed to be responsible for the cognitive deficits in individuals with SCI.

This section reviews the studies reporting the effect of a concomitant TBI with an SCI. Eleven studies met the criteria (table 2). 10,24,28,32-34,41,42,45-47 Pioneering work by Davidoff et al. ${ }^{24}$ showed that acutely after SCI, individuals without a TBI committed fewer errors on HCT compared to those with a concurrent or premorbid TBI. Wilmot et al. ${ }^{10}$ also showed that $64 \%$ of patients with SCI and a concomitant TBI scored as impaired on multiple neuropsychological tests. Richards et al. ${ }^{45}$ tested individuals at 7 and 38 weeks post SCI and reported cognitive improvement in the same degree and pattern consistent with that reported in TBI cases. Following this, Strubreither et al. ${ }^{28}$ reported that $20.2 \%$ of SCI participants had an associated TBI and $72.3 \%$ of SCI + TBI cases showed impairment in performance and personality tests. Similarly, a study by Tolonen et al. ${ }^{32}$ showed $74 \%$ of the SCI sample had a co-occurring TBI and $91 \%$ of SCI + TBI cases showed impaired neuropsychological findings. In 
Table 4 Studies investigating the effect of decentralized cardiovascular control

\begin{tabular}{|c|c|c|}
\hline Author, year & $\begin{array}{l}\text { Cognitive function in relation to cardiovascular } \\
\text { control }\end{array}$ & Control for TBI \\
\hline Jegede et al., $2010^{53}$ & $\begin{array}{l}\text { Memory function was impaired in the hypotensive group } \\
\text { compared to the normotensive group }\end{array}$ & $\begin{array}{l}\text { The incidence of TBI was not different between the } \\
\text { groups ( } 44 \% \text { vs } 45 \%)\end{array}$ \\
\hline Wecht et al., $2012^{67}$ & $\begin{array}{l}\text { Compared to controls, Stroop color test scores were } \\
\text { significantly lower in the paraplegic group and not } \\
\text { different in the tetraplegic group; cognitive function was } \\
\text { associated with systemic hypotension in tetraplegic } \\
\text { cases and inappropriate cerebrovascular reactivity in } \\
\text { paraplegic cases }\end{array}$ & $\begin{array}{l}\text { One individual had a confirmed history of TBI and } 4 \\
\text { individuals had no history of TBI; history of TBI was } \\
\text { unknown for remaining participants; the authors } \\
\text { acknowledged that the effect of TBI cannot be ruled } \\
\text { out }\end{array}$ \\
\hline Phillips et al., $2014^{69}$ & $\begin{array}{l}\text { Individuals with } \mathrm{SCl} \text { scored lower on verbal fluency task; } \\
\text { cognitive functioning was improved with improvements } \\
\text { in blood pressure and neurovascular coupling }\end{array}$ & $\begin{array}{l}\text { Individuals with severe TBI were excluded; one } \\
\text { participant had minor brain injury due to fall from } \\
\text { wheelchair and the follow-up imaging was negative }\end{array}$ \\
\hline Wecht et al., $2016^{68}$ & $\begin{array}{l}\text { Test performance was poorer in } \mathrm{SCl} \text {; antihypotensive } \\
\text { treatment showed no improvements in cognitive } \\
\text { performance }\end{array}$ & Information not provided \\
\hline Varas-Diaz et al., $2017^{70}$ & $\begin{array}{l}\text { Poorer cognitive performance did not correlate with } \\
\text { autonomic measures such as heart rate variability or } \\
\text { root mean square of successive differences of RR } \\
\text { intervals }\end{array}$ & Information not provided \\
\hline
\end{tabular}

Abbreviations: $\mathrm{SCl}$ = spinal cord injury; $\mathrm{TBI}$ = traumatic brain injury.

a subsequent report by Bradbury et al., ${ }^{33}$ participants with SCI performed better than those with SCI + TBI on a neuropsychological test battery, but the 2 groups were indistinguishable on the FIM scale due to the aforementioned ceiling effect.

A series of 4 publications by Macciocchi et al. ${ }^{34,42,46,47}$ also reported the effect of co-occurring TBI on cognition after SCI. The first study reported significantly impaired cognition (FIM) in those with SCI + TBI at both admission and discharge compared to those with SCI alone. ${ }^{47}$ The second study showed that cognitive function (FIM) after SCI was inversely proportional to increase in TBI severity. ${ }^{42}$ The third study further examined a subset of this sample using a battery of neuropsychological tests in addition to FIM. ${ }^{46}$ Testing revealed TBI to have an exacerbating effect on post-SCI cognitive sequelae, with severe TBI in cases of paraplegia and moderate/severe TBI in cases of tetraplegia. Interestingly, the fourth study revealed no significant effect of mild TBI on cognitive impairment after SCI. ${ }^{34}$

Finally, Nott et al. ${ }^{41}$ reported that participants with SCI or SCI + TBI showed no cognitive impairment and received near maximum scores on a cognitive FIM scale, with higher scores than injury severity-matched individuals in the TBI alone group.

Despite some discrepancies, it is evident that a concomitant TBI exacerbates cognitive impairment after SCI. The severitydependent effect of TBI is also supported. The choice of

Table 5 Studies investigating the correlation with age

\begin{tabular}{|c|c|c|}
\hline Author, year & Participants (age) & Correlation \\
\hline Tun et al., $1997^{51}$ & $\begin{array}{l}23 \text { Younger adults ( } 25-55 \text { years; mean } 39.9) \text { and } 23 \\
\text { elderly adults ( } 61-73 \text { years; mean } 67.1 \text { ) with SCI }\end{array}$ & Younger adults performed significantly better on all tests \\
\hline New et al., $2007^{82}$ & $70 \mathrm{SCI}$ ( $47 \%$ over 60 years, $11 \%$ under 40 years) & $\begin{array}{l}\text { Negative correlation between age and FIM cognition } \\
\text { scores }\end{array}$ \\
\hline Jegede et al., $2010^{53}$ & $\begin{array}{l}20 \mathrm{SCl}(11 \text { hypotensive; mean age } 39 \text { years, } 9 \\
\text { normotensive; mean age } 46 \text { years) }\end{array}$ & No correlation of age was observed \\
\hline Schembri et al., $2016^{79}$ & $104 \mathrm{SCl}$ (mean age 45.6 years) & $\begin{array}{l}\text { Younger participants had reduced associations between } \\
\text { sleep apnea and cognitive impairment }\end{array}$ \\
\hline Craig et al., $2017^{14}$ & $150 \mathrm{SCl}$ (mean age 46.2 years) & $\begin{array}{l}\text { Weak negative correlation with NUCOG total ( } r=-0.14 \text {, } \\
p<0.05) \text {, memory }(r=-0.26, p<0.05) \text {, and executive } \\
\text { function }(r=-0.22, p<0.05) \text {; no correlation with } \\
\text { attention, language, or visuoconstruction }\end{array}$ \\
\hline
\end{tabular}

Abbreviations: FIM = Functional Independence Measure; NUCOG = Neuropsychiatry Unit Cognitive Assessment Tool; SCI = spinal cord injury. 
Table 6 Studies examining the correlation with lesion level

\begin{tabular}{|c|c|c|}
\hline Author, year & Participants/lesion characteristics & Correlation \\
\hline Wilmot et al., $1985^{10}$ & 67 SCl; C2-4 (26.9\%), C5-8 (49.1\%), T1-7 (12\%), below T8 (12\%) & No correlation was observed \\
\hline Richards et al., $1988^{45}$ & $150 \mathrm{SCl}$ (48.7\% with paraplegia, 51.3\% with tetraplegia) & $\begin{array}{l}\text { Tetraplegic individuals performed similar to those with } \\
\text { paraplegia with a few exceptions (exact number not } \\
\text { specified); overall, no correlation was observed }\end{array}$ \\
\hline Copes et al., $1996^{84}$ & $94 \mathrm{SCl}$ (53.2\% with paraplegia, $46.8 \%$ with paraplegia) & No correlation was observed \\
\hline Tun et al., $1997^{51}$ & $\begin{array}{l}23 \text { Younger adults ( } 4 \text { cervical, } 19 \text { thoracolumbar) and } 23 \text { elderly } \\
\text { adults ( } 9 \text { cervical, } 14 \text { thoracolumbar) with SCl }\end{array}$ & No correlation was observed \\
\hline Middleton et al., $1998^{85}$ & 112 SCl; C1-4 (11), C5 (19), C6 (24), C7-8 (7), T1-6 (13), below T7 (38) & No correlation was observed \\
\hline Hall et al., $1999^{29}$ & $\begin{array}{l}\text { 3,971 SCl; C1-3 (156), C4 (517), C5 (578), C6 (313), C7 (177), C8 (55), } \\
\text { thoracic (1718), lumbar/sacral (457) }\end{array}$ & No correlation was observed \\
\hline Masedo et al., $2005^{37}$ & 84 SCl; cervical (53.6\%), thoracic (38.1\%), lumbar/sacral (7.1\%) & No correlation was observed \\
\hline $\begin{array}{l}\text { Samuelkamleshkumar } \\
\text { et al., } 2010^{86}\end{array}$ & 104 SCl; T6 and above (30), T7 and below (74) & No correlation was observed \\
\hline $\begin{array}{l}\text { Macciocchi et al., } \\
2012^{46}\end{array}$ & $189 \mathrm{SCl}$ (93 with paraplegia, 96 with tetraplegia) & No correlation was observed \\
\hline Wecht et al., $2012^{67}$ & $13 \mathrm{SCl} ; \mathrm{C} 4-8(7), \mathrm{T} 2-10(6)$ & $\begin{array}{l}\text { Paraplegic individuals were more impaired than } \\
\text { tetraplegic ones }\end{array}$ \\
\hline Lazzaro et al., $2013^{87}$ & $37 \mathrm{SCl}$ (27 with paraplegia and 10 with tetraplegia) and 37 controls & $\begin{array}{l}\text { Response time in the tetraplegic group was significantly } \\
\text { more delayed than in the paraplegic group }\end{array}$ \\
\hline Barbetta et al., $2014^{88}$ & 218 SCl; cervical (62), thoracic (127), lumbar (29) & No correlation was observed \\
\hline Zonfrillo et al., $2014^{38}$ & 2,190 SCl; paraplegic $(1,244)$, quadriplegic (946) & No correlation was observed \\
\hline Craig et al., $2017^{14}$ & $150 \mathrm{SCl}$ (42\% with paraplegia, 58\% with tetraplegia) & No correlation was observed \\
\hline
\end{tabular}

Abbreviations: $\mathrm{C}$ = cervical spinal level; $\mathrm{SCl}=$ spinal cord injury; $\mathrm{T}$ = thoracic spinal level.

cognitive test appears to play a major role in determining the outcomes in this category.

\section{Association with psychological and somatic comorbidities}

SCI is associated with an elevated risk of psychological morbidities in contrast to a normal process of grief because of the devastating nature of the event or simply a stage in the adjustment process. ${ }^{48,49}$ The association of SCI with psychological morbidities such as anxiety, depression, distress, and posttraumatic stress disorder has been extensively reviewed ${ }^{2,11,12}$ but their comorbid effect on cognitive capacity has not yet been discussed. This section reviews the effect of psychological disorders on cognitive functions after SCI. Studies examining psychological disorders after SCI were excluded if they did not include a cognitive assessment or an assessment of correlation. A total of 9 studies are discussed here (table 3). ${ }^{14,27,50-56}$

Six studies examined the association with depression. ${ }^{50,51,53-56}$ While 3 studies showed no correlation, ${ }^{51,53,54}$ the other 3 showed significant negative correlation between severity of depression and cognitive capacity. ${ }^{50,55,56}$ Most striking among the latter 3 was the study by Craig et al. ${ }^{55}$ that showed cognitive capacity was a strong predictor of psychological disorders postdischarge; i.e., participants with higher cognitive capacity were 6.3 times less likely to experience a psychological disorder 6 months postdischarge.

Three studies showed correlation between pain and decline in self-perceived cognitive ability based on Ruff Neuro-behavioral Inventory, ${ }^{52} \mathrm{NUCOG},{ }^{14}$ or a comprehensive neuropsychological battery. ${ }^{27}$

Three studies examined the association with fatigue. Dowler et al. $^{27}$ reported fatigue to be associated with poorer processing speed based on the somatic complaints subscale of the Minnesota Multiphasic Personality Inventory. The other 2 studies were from Craig et al. ${ }^{14,56}$ : one demonstrated cognition-related fatigue after SCI (Iowa Fatigue Scale) and the other showed no interaction between fatigue (Fatigue Severity Scale) and cognitive function (NUCOG).

For psychological comorbidities, despite the numerous reports of presence of psychological comorbidities after $\mathrm{SCI},{ }^{2,12}$ their association with cognitive decline is investigated by only 6 studies and is supported by only 3 of them. Further, since 2 of the 3 studies included a considerable proportion of individuals with concomitant $\mathrm{TBI}^{55,56}$ and only one had excluded participants with severe $\mathrm{TBI},{ }^{50}$ the contribution of TBI 
cannot be dismissed. For somatic comorbidities, 3 of the 4 studies show an association between cognitive sequelae and somatic abnormalities such as pain and fatigue. Only one of the studies excluded participants with $\mathrm{TBI},{ }^{52}$ hence the effect of TBI on these associations cannot be completely ruled out.

\section{Effect of decentralized cardiovascular control}

Spinal injuries that damage the sympathoregulatory pathways result in impaired vasomotor tone and disordered cardiovascular control. ${ }^{1,5}$ In able-bodied individuals, there is an abundance of literature linking cognitive impairment to altered cardiovascular control, ${ }^{57}$ systemic hypotension, ${ }^{58}$ hypertension, $^{59}$ cerebral hypoperfusion $^{60,61}$ (references 61-123 available from Dryad: doi.org/10.5061/dryad.rj74424), and increased arterial stiffness. ${ }^{62,63}$ It is conceivable that similar mechanisms that are frequent after $\mathrm{SCI}^{64-66}$ may contribute to cognitive impairment. Interestingly, we identified 5 studies investigating the contribution of altered cardiovascular and cerebral vascular control in cognitive impairment after SCI (table 4). ${ }^{53,67-70}$

Jegede et al. ${ }^{53}$ classified participants with SCI (matched for TBI incidence) as hypotensive and normotensive based on 24-hour observation of blood pressure. The hypotensive group was significantly impaired in memory, attention, and processing speed. A follow-up study compared cerebral hemodynamics among paraplegic, tetraplegic, and able-bodied individuals during a Stroop test ${ }^{67}$ (doi.org/10.5061/dryad. rj74424). Surprisingly, this study reported reduced test performance in the paraplegic (and not tetraplegic) group compared to controls without SCI. This unexpected finding was attributed to small sample size, variability in results, and possibly co-occurring TBI. Interestingly, both SCI groups showed increased cerebrovascular resistance and decreased cerebral blood flow ( $\mathrm{CBF}$ ) during the task in contrast to increased CBF in the controls without SCI, suggesting abnormal cerebral hemodynamics and impaired neurovascular coupling after SCI. Based on these findings, this group further showed that although antihypotensive drugs increased mean arterial pressure and $\mathrm{CBF}$ velocity during cognitive tasks in participants with SCI, the test performance did not improve, suggesting the need for further optimization of pharmacotherapy. $^{68}$

Contrary to these findings, our work shows that SCIassociated impairments in systemic and cerebral hemodynamics as well as cognitive function are partially mitigated by the antihypotensive agent midodrine hydrochloride ${ }^{69}$ (doi. org/10.5061/dryad.rj74424). Finally, a recent study by Diaz et al. $^{70}$ reported a lack of correlation between SCI-associated cognitive impairment and various cardiovascular measures.

Relatively recent (2010-2017) evidence suggests there is a correlation between sympathetic cardiovascular decentralization and impaired cognitive outcomes. However, the limited number of studies as well as the considerable dissonance across findings warrant further clarification to delineate the consequences of impaired cardiovascular function on cognitive functioning after SCI. More importantly, the majority of studies did not employ rigorous controls for a head injury (table 4); therefore the contribution of TBI cannot be ruled out.

\section{Effect of sleep apnea}

Obstructive sleep apnea (OSA) is the most common form of sleep breathing disorder among individuals with tetraplegia $^{71}$ (doi.org/10.5061/dryad.rj74424). Arterial oxygen desaturation and sleep disruption cause patients with OSA to present with daytime sleepiness. ${ }^{72-74}$ In able-bodied individuals, hypoxia (e.g., in hypoxemic lung disease $)^{75}$ as well as untreated cases of OSA have been associated with neuropsychological disorders. Moreover, decreased glymphatic clearance of neuronal metabolites due to OSA has also been linked to cognitive decline. ${ }^{76}$ Interestingly, neuropsychological disorders are mitigated upon successful treatment of sleep apnea. ${ }^{77,78}$ It is therefore possible that individuals with SCI and OSA are prone to cognitive impairment.

We identified 2 studies that examined the association between sleep apnea and cognitive deficits after $\mathrm{SCI}^{79,80}$ (doi.org/ 10.5061/dryad.rj74424). Sajkov et al. ${ }^{79}$ administered a neuropsychological test battery on participants with tetraplegia while excluding the cases with a co-occurring TBI. Although no direct relationship was found between sleep apnea and cognitive impairment, severe oxygen desaturation $\left(\mathrm{SaO}_{2}\right.$ $<80 \%$ ) was associated with impaired attention, concentration, immediate and short-term memory, cognitive flexibility, internal scanning, and working memory. More recently, Schembri et al. ${ }^{80}$ classified participants with tetraplegia (with no TBI) based on the severity of sleep apnea and administered a similar battery of tests. Participants with more severe sleep apnea performed worse on the attention, information processing, and immediate recall tasks compared to mild/ moderate groups.

Both studies suggest that sleep-disordered breathing is common after SCI and is associated with oxygen desaturation. While one study reports a direct association between severities of sleep apnea and cognitive impairment ${ }^{80}$ (doi.org/ 10.5061/dryad.rj74424), the other suggests that nocturnal oxygen desaturation could impair daytime cognitive functioning. ${ }^{79}$ A major strength of both studies was the exclusion of individuals with TBI.

\section{Effect of age}

Medical and technological advancements over decades have led to substantially increased life expectancy of individuals with SCI $^{81}$ (doi.org/10.5061/dryad.rj74424). Yet with this increase, individuals' SCI-associated impairments are prone to be compounded by the numerous physiologic and psychological changes experienced in the general population. Therefore, it is of clinical significance to understand the effect of age on cognitive impairment after SCI. 
Five studies reported the investigation of age in cognitive impairment following SCI (table 5) $14,51,53,80,82$ (doi.org/10. 5061/dryad.rj74424). While one study did not show a correlation between age and any of the tests from a neuropsychological test battery, ${ }^{53}$ a further 3 studies showed significant cognitive decline in elderly participants $(>60$ years) compared to younger ones ( $<40$ years) across a cognitive test battery ${ }^{51,80}$ as well as on the FIM instrument. ${ }^{82}$ Finally, one study using the NUCOG test reported that age was negatively correlated with memory and executive functions but not with attention, language, or visuoconstruction function. ${ }^{14}$

Four out of five studies support a greater prevalence of increase in SCI-associated cognitive impairment with increasing age.

\section{Correlation with neurologic level of injury}

It is generally accepted that physical and physiologic disability increases as a function of higher neurologic level of spinal lesion $^{83}$ (doi.org/10.5061/dryad.rj74424). Moreover, with newer studies highlighting the effect of higher-level SCIrelated issues (e.g., cardiovascular dysfunction) on cognitive impairment, it is imperative to review the association between level of lesion and cognitive impairment.

Of the 14 studies analyzing the severity of cognitive impairment in relation to injury level (table 6) $10,14,29,37,38,45,46,51,67,84-88$ (doi.org/10.5061/dryad.rj74424), 12 studies showed no effect of injury level on the extent of cognitive impairment. $10,14,29,37,38,45,46,51,84-86,88$ One study showed that response time was delayed in quadriplegic individuals compared to paraplegics on auditory button-press oddball discrimination paradigm. ${ }^{87}$ In contrast, Wecht et al. ${ }^{67}$ showed that quadriplegic individuals performed better on the Stroop test than paraplegic individuals.

The majority of studies show no correlation between injury level and cognitive decline.

\section{Limitations of the existing literature and research implications}

This review revealed that individuals with SCI have significant cognitive impairment. However, substantial variability across the studies makes it challenging to conclude the incidence rates of cognitive impairment in this population. One such variation is the number of participants across the studies, which ranged between 9 and 233,778. This needs to be taken into consideration before concluding and interpreting the findings. Another factor contributing to variable results is the choice of test administered, i.e., FIM vs comprehensive neuropsychological testing. When using FIM to test cognitive functioning after SCI, researchers and practitioners need to consider that the FIM instrument was developed to assess impairment across diverse disability groups. Moreover, cognition subscales of FIM are largely based on bedside observations of patient behavior, which arguably lacks the sensitivity of a systematic neuropsychological evaluation. This argument was supported by a blinded study by Davidoff et al., ${ }^{26}$ which showed that cognition scores on FIM did not correlate with any of the test scores from a neuropsychological battery within the same set of participants. Unsurprisingly, this apparent lack of sensitivity resulting in a ceiling effect (i.e., most patients scoring near maximum range on the FIM scale) was also reported by many other studies (table 1). This warrants the need for a wider scientific community to establish a standardized testing protocol, which is not only sensitive to various domains of cognition, but is also easy to implement in a clinical setting. Moreover, these tools need to be tested for reliability in this specialized population of interest.

Another major limitation is the inadequate control for a concomitant TBI. Owing to the etiologic similarities, the cooccurrence of TBI and SCI is inevitable, reported in up to $60 \%$ of SCI cases. ${ }^{42,43}$ Although TBI explains the cognitive impairment after SCI, it also confounds the contribution of other potential factors. Many studies attempting to examine the role of confounding factors are plagued by the lack of adequate controls for TBI. For example, the contribution of TBI could not be ruled out in the majority of studies investigating the association with psychological/somatic comorbidities (table 3) or the effect of decentralized cardiovascular control (table 4). This appears to be a major methodologic limitation in otherwise well-designed studies. We hope that this review encourages future studies to use stringent inclusion criteria for participants and meticulous analyses of individuals with spinal cord pathologies where TBI is less likely, e.g., motor vehicle accidents vs gunshot wound injuries as well as nontraumatic cases (e.g., neoplasia, stroke, infection, inflammation).

Finally, some other limitations of current studies can be addressed by future research. For instance, potential interactions between one or more comorbidities needs further examination, e.g., patterns of psychological impairment and its interaction with TBI or sleep apnea. In addition, given the effect of cardiovascular and cerebrovascular dysfunction, more sensitive noninvasive diagnostic methods, e.g., arterial spin labeling-MRI, could be used to investigate small vessel disease burden and white matter abnormalities, which may play a role in cognitive decline post SCI.

\section{Clinical implications}

Successful SCI rehabilitation relies heavily on the patient's acquisition of novel skills that are crucial for survival, self-care, mobility, and overall well-being following discharge. Quick and reliable learning of these skills can be a major challenge if the patient has cognitive impairment. Evaluation of cognitive problems may allow the patient education to be tailored accordingly. For instance, single demonstration of a task may be adequate for a cognitively intact individual, but those with cognitive impairment may require frequent repetitions of the task, simpler instructions, and auditory/visual reminders. 
Other factors to be considered may include the consistency of instructions given, format of instructions (e.g., in group settings vs one-on-one sessions), and the patient's ability to understand supplemental literature if provided. ${ }^{3}$

In addition to modifying existing rehabilitation programs, novel specialized therapies may be implemented to improve cognitive health. Encouraging results from TBI rehabilitation programs show improvement not only in memory, attention, and problem-solving, but also in mood disturbances and anger management $^{89,90}$ (doi.org/10.5061/dryad.rj74424). Moreover, specialized psychological treatment programs (e.g., cognitive behavioral therapy) in individuals with SCI have also shown both short- and long-term effects in immunizing against anxiety and depression. ${ }^{91,92}$ Broader application of similar therapies may improve cognitive well-being and overall quality of life after SCI.

It has been acknowledged that SCI has far-reaching effects and can pose considerable emotional stress for family members and rehabilitation staff. ${ }^{2}$ Caregiving spouses report more physical and emotional stress, burnout, fatigue, anger, and resentment compared to spouses who were not caregivers ${ }^{93}$ (doi.org/10. 5061/dryad.rj74424). Similar psychological effects have also been reported for the nursing staff. ${ }^{94,95}$ It is therefore of great importance for family members to be educated about these consequences of SCI, as they often tend to focus on more overt physical outcomes of SCI and are unaware that cognitive impairment may reduce independence and require more care. It is also vital for the rehabilitation staff to recognize that SCI is associated with mood/personality issues and impaired learning ability. Having a realistic view of expectations may lower the stress levels for family members and staff.

\section{Discussion}

This systematic review offers a broad picture of negative cognitive sequelae following SCI and highlights various contributing factors. We also attempt to underline some of the major methodologic issues responsible for discrepancies across studies, which confound the synthesis of broader conclusions from the currently available evidence base. Nevertheless, there is a substantial amount of evidence portraying the severity of the cognitive problems in individuals with SCI. Consequently, there is an urgent need for further research in this area. Future research should consider adopting more rigorous controls to account for TBI when examining participants with SCI. Clinical implications encompass superior rehabilitation standards or dedicated neuropsychological therapies that will likely benefit the patients as well as the caregivers.

\section{Author contributions}

R. Sachdeva: study design, literature search, analysis, manuscript writing and editing. F. Gao: study design, manuscript editing. C.C.H. Chan: study design, manuscript editing. A.V. Krassioukov: study design, literature search, analysis, manuscript writing and editing.

\section{Acknowledgment}

The authors thank Drs. John Houle, Matthias Walter, and Tom Nightingale for reviewing the manuscript.

\section{Study funding}

Dr. Krassioukov's laboratory is supported by funds from the Canadian Institute for Health Research, Heart and Stroke Foundation, Canadian Foundation for Innovation, BC Knowledge Development Fund, and the Craig H. Neilsen Foundation. Dr. Sachdeva is supported by a Craig H. Neilsen Foundation Postdoctoral Fellowship and Bluma Tischler Postdoctoral Fellowship (University of British Columbia). The study was partly supported by an internal research grant (awarded to Dr. Chan) from Hong Kong Polytechnic University.

\section{Disclosure}

The authors report no disclosures relevant to the manuscript. Go to Neurology.org/N for full disclosures.

Received January 9, 2018. Accepted in final form June 6, 2018.

\section{References}

1. Biering-Sorensen F, Biering-Sorensen T, Liu N, Malmqvist L, Wecht JM, Krassioukov A. Alterations in cardiac autonomic control in spinal cord injury. Auton Neurosci 2018;209:4-18.

2. North NT. The psychological effects of spinal cord injury: a review. Spinal Cord 1999; 37:671-679.

3. Warren AM, Pullins J, Elliott TR. Concomitant cognitive impairment in persons with spinal cord injuries in rehabilitation settings. In: Neuropsychology within the Inpatient Rehabilitation Environment. Hauppauge: Nova Science Publishers; 2008.

4. Davidoff GN, Roth EJ, Richards JS. Cognitive deficits in spinal cord injury: epidemiology and outcome. Arch Phys Med Rehabil 1992;73:275-284.

5. Krassioukov A. Autonomic function following cervical spinal cord injury. Respir Physiol Neurobiol 2009;169:157-164.

6. History of treatment of spinal cord injuries. MD State Med J 1970;19:109-112.

7. Middleton JW, Dayton A, Walsh J, Rutkowski SB, Leong G, Duong S. Life expectancy after spinal cord injury: a 50-year study. Spinal Cord 2012;50:803-811.

8. Krause JS. Spinal cord injury and its rehabilitation. Curr Opin Neurol Neurosurg 1992;5:669-672.

9. Schonherr MC, Groothoff JW, Mulder GA, Eisma WH. Functional outcome of patients with spinal cord injury: rehabilitation outcome study. Clin Rehabil 1999;13: $457-463$.

10. Wilmot CB, Cope DN, Hall KM, Acker M. Occult head injury: its incidence in spinal cord injury. Arch Phys Med Rehabil 1985;66:227-231.

11. Sakakibara BM, Miller WC, Orenczuk SG, Wolfe DL, Team SR. A systematic review of depression and anxiety measures used with individuals with spinal cord injury. Spinal Cord 2009;47:841-851.

12. Craig A, Tran Y, Middleton J. Psychological morbidity and spinal cord injury: a systematic review. Spinal Cord 2009;47:108-114.

13. van Leeuwen CM, Kraaijeveld S, Lindeman E, Post MW. Associations between psychological factors and quality of life ratings in persons with spinal cord injury: a systematic review. Spinal Cord 2012;50:174-187.

14. Craig A, Guest R, Tran Y, Middleton J. Cognitive impairment and mood states after spinal cord injury. J Neurotrauma 2017;34:1156-1163.

15. Craig A, Nicholson Perry K, Guest R, Tran Y, Middleton J. Adjustment following chronic spinal cord injury: determining factors that contribute to social participation. Br J Health Psychol 2015;20:807-823.

16. Morris J, Roth E, Davidoff G. Mild closed head injury and cognitive deficits in spinalcord-injured patients: incidence and impact. J Head Trauma Rehabil 1986;1:31-42.

17. Fee FA. Psychosocial consequences of concomitant spinal cord injury and traumatic brain injury. SCI Psychosocial Process 1995;8:106-111.

18. Wecht JM, Bauman WA. Decentralized cardiovascular autonomic control and cognitive deficits in persons with spinal cord injury. J Spinal Cord Med 2013;36:74-81.

19. Bauman WA, Korsten MA, Radulovic M, Schilero GJ, Wecht JM, Spungen AM. 31st G. Heiner sell lectureship: secondary medical consequences of spinal cord injury. Top Spinal Cord Inj Rehabil 2012;18:354-378. 
20. Liberati A, Altman DG, Tetzlaff J, et al. The PRISMA statement for reporting systematic reviews and meta-analyses of studies that evaluate health care interventions: explanation and elaboration. J Clin Epidemiol 2009;62:e1-34.

21. Radanov BP, Dvorak J, DiStefano G. Attentional processing in common whiplash syndrome before and with immobilisation of the cervical spine. Eur Spine J 1993;2: $72-75$.

22. Wingfield A, Tun CG, Gomez PT, Tun PA. Preservation of cognitive function after long-term tetraplegia. Am J Phys Med Rehabil 2003;82:547-555.

23. Chambers D, Rodgers M, Woolacott N. Not only randomized controlled trials, but also case series should be considered in systematic reviews of rapidly developing technologies. J Clin Epidemiol 2009;62:1253-1260.

24. Davidoff G, Morris J, Roth E, Bleiberg J. Cognitive dysfunction and mild closed head injury in traumatic spinal cord injury. Arch Phys Med Rehabil 1985;66: 489-491.

25. Roth E, Davidoff G, Thomas P, et al. A controlled study of neuropsychological deficits in acute spinal cord injury patients. Paraplegia 1989;27:480-489.

26. Davidoff GN, Roth EJ, Haughton JS, Ardner MS. Cognitive dysfunction in spinal cord injury patients: sensitivity of the Functional Independence Measure subscales vs neuropsychologic assessment. Arch Phys Med Rehabil 1990;71:326-329.

27. Dowler RN, O’Brien SA, Haaland KY, Harrington DL, Feel F, Fiedler K. Neuropsychological functioning following a spinal cord injury. Appl Neuropsychol 1995;2:124-129.

28. Strubreither W, Hackbusch B, Hermann-Gruber M, Stahr G, Jonas HP. Neuropsychological aspects of the rehabilitation of patients with paralysis from a spinal injury who also have a brain injury. Spinal Cord 1997;35:487-492.

29. Hall KM, Cohen ME, Wright J, Call M, Werner P. Characteristics of the Functional Independence Measure in traumatic spinal cord injury. Arch Phys Med Rehabil 1999; 80:1471-1476.

30. Borgaro SR, Kwasnica C, Cutter N, Alcott S. The use of the BNI screen for higher cerebral functions in assessing disorientation after traumatic brain injury. $\mathrm{J}$ Head Trauma Rehabil 2003;18:284-291.

31. Holtslag HR, van Beeck EF, Lindeman E, Leenen LP. Determinants of long-term functional consequences after major trauma. J Trauma Injury Infect Crit Care 2007; 62:919-927.

32. Tolonen A, Turkka J, Salonen O, Ahoniemi E, Alaranta H. Traumatic brain injury is under-diagnosed in patients with spinal cord injury. J Rehabil Med 2007;39:622-626.

33. Bradbury CL, Wodchis WP, Mikulis DJ, et al. Traumatic brain injury in patients with traumatic spinal cord injury: clinical and economic consequences. Arch Phys Med Rehabil 2008;89:S77-S84.

34. Macciocchi SN, Seel RT, Thompson N. The impact of mild traumatic brain injury on cognitive functioning following co-occurring spinal cord injury. Arch Clin Neuropsychol 2013;28:684-691.

35. Purohit M, Goldstein R, Nadler D, et al. Cognition in patients with burn injury in the inpatient rehabilitation population. Arch Phys Med Rehabil 2014;95:1342-1349.

36. Dowler RN, Harrington DL, Haaland KY, Swanda RM, Fee F, Fiedler K. Profiles of cognitive functioning in chronic spinal cord injury and the role of moderating variables. J Int Neuropsychol Soc 1997;3:464-472.

37. Masedo AI, Hanley M, Jensen MP, Ehde D, Cardenas DD. Reliability and validity of a self-report FIM (FIM-SR) in persons with amputation or spinal cord injury and chronic pain. Am J Phys Med Rehabil 2005;84:167-176

38. Zonfrillo MR, Durbin DR, Winston FK, Zhang X, Stineman MG. Residual cognitive disability after completion of inpatient rehabilitation among injured children.J Pediatr 2014;164:130-135.

39. Yarkony GM, Formal CS, Cawley MF. Spinal cord injury rehabilitation: 1: assessment and management during acute care. Arch Phys Med Rehabil 1997;78:S48-S52.

40. Sorenson SB, Kraus JF. Occurrence, severity, and outcomes of brain injury. J Head Trauma Rehabil 1991;6:1-10.
41. Nott MT, Baguley IJ, Heriseanu R, et al. Effects of concomitant spinal cord injury and brain injury on medical and functional outcomes and community participation. Top Spinal Cord Inj Rehabil 2014;20:225-235.

42. Macciocchi S, Seel RT, Thompson N, Byams R, Bowman B. Spinal cord injury and cooccurring traumatic brain injury: assessment and incidence. Arch Phys Med Rehabil $2008 ; 89: 1350-1357$.

43. Michael DB, Guyot DR, Darmody WR. Coincidence of head and cervical spine injury. J Neurotrauma 1989;6:177-189.

44. Millis SR, Rosenthal M, Novack TA, et al. Long-term neuropsychological outcome after traumatic brain injury. J Head Trauma Rehabil 2001;16:343-355.

45. Richards JS, Brown L, Hagglund K, Bua G, Reeder K. Spinal cord injury and concomitant traumatic brain injury: results of a longitudinal investigation. Am J Phys Med Rehabil 1988;67:211-216.

46. Macciocchi S, Seel RT, Warshowsky A, Thompson N, Barlow K. Co-occurring traumatic brain injury and acute spinal cord injury rehabilitation outcomes. Arch Phys Med Rehabil 2012;93:1788-1794.

47. Macciocchi SN, Bowman B, Coker J, Apple D, Leslie D. Effect of co-morbid traumatic brain injury on functional outcome of persons with spinal cord injuries. Am J Phys Med Rehabil 2004;83:22-26.

48. Craig AR, Hancock KM, Dickson HG. A longitudinal investigation into anxiety and depression in the first 2 years following a spinal cord injury. Paraplegia 1994;32:675-679.

49. Orbaan IJ. Psychological adjustment problems in people with traumatic spinal cord lesions. Acta Neurochir 1986;79:58-61.

50. Shnek ZM, Foley FW, LaRocca NG, et al. Helplessness, self-efficacy, cognitive distortions, and depression in multiple sclerosis and spinal cord injury. Ann Behav Med 1997; 19:287-294.

51. Tun CG, Tun PA, Wingfield A. Cognitive function following long-term spinal cord injury. Rehabil Psychol 1997;42:163-182.

52. Murray RF, Asghari A, Egorov DD, et al. Impact of spinal cord injury on self-perceived pre- and postmorbid cognitive, emotional and physical functioning. Spinal Cord 2007; 45:429-436.

53. Jegede $\mathrm{AB}$, Rosado-Rivera $\mathrm{D}$, Bauman WA, et al. Cognitive performance in hypotensive persons with spinal cord injury. Clin Auton Res 2010;20:3-9.

54. Clarke LA, Genat RC, Anderson JFI. Long-term cognitive complaint and postconcussive symptoms following mild traumatic brain injury: the role of cognitive and affective factors. Brain Inj 2012;26:298-307 210p.

55. Craig A, Nicholson Perry K, Guest R, et al. Prospective study of the occurrence of psychological disorders and comorbidities after spinal cord injury. Arch Phys Med Rehabil 2015;96:1426-1434.

56. Craig A, Tran Y, Wijesuriya N, Middleton J. Fatigue and tiredness in people with spinal cord injury. J Psychosomatic Res 2012;73:205-210.

57. Duschek S, Muckenthaler M, Werner N, del Paso GA. Relationships between features of autonomic cardiovascular control and cognitive performance. Biol Psychol 2009; 81:110-117.

58. Duschek S, Matthias E, Schandry R. Essential hypotension is accompanied by deficits in attention and working memory. Behav Med 2005;30:149-158.

59. Obisesan TO, Obisesan OA, Martins S, et al. High blood pressure, hypertension, and high pulse pressure are associated with poorer cognitive function in persons aged 60 and older: the Third National Health and Nutrition Examination Survey.J Am Geriatr Soc 2008;56:501-509.

60. Duschek S, Hadjamu M, Schandry R. Enhancement of cerebral blood flow and cognitive performance following pharmacological blood pressure elevation in chronic hypotension. Psychophysiology 2007;44:145-153.

Data available from Dryad (references 61-123): https://doi.org/10.5061/dryad. rj74424.

\section{Get 10 AAN Practice Management Webinars for Less than \$19 Each}

The AAN is dedicated to helping neurologists improve their practices and delivery of quality care to their patients. The AAN's Practice Management Webinars provide the valuable insights and tools you need to navigate through the ever-changing health care landscape —and receive year-end CME credits!

Purchase webinars individually for $\$ 99$ each, or subscribe to the complete series of 2018 webinars for only $\$ 189$-that's less than $\$ 19$ per webinar! See the list of webinars and subscribe at AAN.com/view/pmw18. 